\title{
LETRAMENTO LITERÁRIO E FORMAÇÃO DO LEITOR NO CONTEXTO ESCOLAR
}

\author{
Sônia Moreira Coutinho'
}

\begin{abstract}
Resumo: Neste trabalho, apresentamos uma reflexão sobre a complexa e importante tarefa da escola que é formar leitores de literatura. Inicialmente, evidenciamos duas principais abordagens de leitura, no campo da Linguística Aplicada: a psicossocial, que se fundamenta nas ciências psicológicas (Psicolinguística e Psicologia Cognitiva) e a sócio-histórica, com destaque para a concepção de leitura proposta pelos Novos Estudos do Letramento, que concebe a leitura como uma prática social circunscrita aos contextos reais de usos da língua (STREET, 2014). Pretendemos demonstrar como essas abordagens impactaram ou impactam o trabalho com leitura nas escolas. Em seguida, discutimos de maneira mais específica as contribuições dos estudos do letramento com ênfase nos pressupostos do Letramento Literário para o ensino de literatura nas escolas. Nessa perspectiva, o trabalho com a leitura deve considerar os seguintes princípios: a "experiência do literário", "não se reduzir ao sistema canônico" e a "construção de uma comunidade de leitores" (COSSON, 2012, 2014). Por fim, propomos o círculo de leitura como uma prática de letramento literário que pode contribuir para a formação de leitores críticos e proficientes, no contexto escolar.
\end{abstract}

Palavras-chave: Formação do leitor. Leitura literária. Letramento literário. Concepções de leitura.

\section{Introdução}

A leitura é fundamental para a participação plena das pessoas na sociedade letrada contemporânea. Tanto no espaço público, quanto no privado, as pessoas estão sujeitas a diversas práticas que envolvem os usos da escrita, exigindo delas certa habilidade para construção dos sentidos dos gêneros textuais que lhes chegam, nas mais variadas situações de interação social.

Considerando a relação do leitor com a multiplicidade de textos que circulam na sociedade, AZEVEDO defende que: (2004, p: 38)

[...] leitores são simplesmente pessoas que sabem usufruir os diferentes tipos de livros, as diferentes "literaturas" - científicas, artísticas, didáticoinformativas, religiosas, técnicas entre outras - existentes por aí. Conseguem, portanto, diferenciar uma obra literária e artística de um texto científico; ou uma obra filosófica de uma informativa. Leitores podem ser descritos como pessoas aptas a utilizar textos em benefício próprio, seja por motivação, seja para receber informações, seja como instrumento para ampliar sua visão de mundo, seja por motivos religiosos, seja por puro e simples entretenimento.

\footnotetext{
${ }^{1}$ Professora Assistente B, da Universidade Estadual de Feira de Santana. Licenciada em Letras com Francês pela UEFS (1985), mestre em Letras pela UFBA (2005), doutoranda em Linguística Aplicada IEL-UNICAMP.
}

Revista de Letras JUÇARA, Caxias - Maranhão, v. 03, n. 02, p. 58 - 75, dez. $2019 \mid 58$ 
A partir desse pressuposto podemos afirmar que todas as leituras são válidas, têm sua importância, assim como não existe apenas um tipo de leitor, e que, o contato do leitor com os textos deve the servir como momento para a construção de novos saberes, de novas experiências estéticas e subjetivas, contribuindo sobremaneira para a construção de si próprio e de sua relação com o mundo.

Apesar da importância dessas leituras para a constituição do sujeito leitor, não podemos compreendê-las todas do mesmo modo devido às suas especificidades e funções na sociedade. Assim, no processo de formação de leitores, dentre os vários tipos de leitura, queremos destacar aqui a relevância da leitura de função estética, ou seja, a leitura literária, "aquela que remete à ficção e ao discurso poético". (AZEVEDO, p. 40)

Aquela que deslocada da objetividade e impessoalidade de certos discursos cria, pela linguagem, outras formas de os leitores se relacionarem com os textos e com sua realidade. Conforme observamos nas palavras de LEAHY: (2008, p. 211-212)

\footnotetext{
O artista, o poeta, o escritor literário são aqueles que sentem, aqueles que penetram na realidade e desenvolvem seus conhecimentos não apenas pela via da razão e da lógica, mas, também, da sensibilidade, da emoção, da intuição... tão importantes quanto a razão. São formas outras de se apropriar do mundo e do conhecimento.
}

Para uma grande maioria dos jovens e crianças de nosso país, o acesso a determinados bens culturais, como o livro, em particular o de literatura, não faz parte de sua vida cotidiana, cabendo à escola papel importante para oportunizar aos seus educandos o contato com esse tipo de leitura.

Nesse contexto, a formação do leitor estará de certa forma vinculada à maneira como as instituições de ensino concebem suas práticas leitoras, como organizam os modos de ler nesses espaços, sobretudo, no que concerne ao trabalho com os textos literários.

\section{Concepções de leitura e de leitor}

Revista de Letras JUÇARA, Caxias - Maranhão, v. 03, n. 02, p. 58 - 75, dez. 2019 | 59 
Segundo SILVA (1999), o modo como concebemos determinado processo afeta diretamente nossa maneira de agir na prática. Desse modo, o trabalho com a leitura na escola será desenvolvido de acordo com as concepções de leitura adotadas pelos educadores em sua prática pedagógica.

Estudiosos da área têm apresentado várias concepções de leitura e de leitor, decorrentes dos avanços dos estudos linguísticos e das afiliações teóricas que esses adotam. No âmbito da Linguística Aplicada, duas grandes vertentes se destacam nas pesquisas sobre leitura, e suas consequências para o ensino, no Brasil: uma abordagem psicossocial e outra abordagem sócio-histórica. (KLEIMAN, 2004)

A abordagem psicossocial se assenta nos pressupostos das ciências psicológicas (a Psicolinguística e a Psicologia Cognitiva) com o intuito de descrever como funcionam os processos cognitivos realizados pelo leitor para proceder à compreensão do texto. A leitura é concebida como um processo psicológico em que o leitor utiliza diversas estratégias cognitivas (processo inconsciente realizado pelo leitor para interpretar as marcas formais do texto) e metacognitivas (delimitação dos objetivos da leitura, levantamento de hipóteses) que constituem $o$ ato de compreender.

A ênfase são para os "[...] aspectos ligados à relação entre o sujeito leitor e o texto enquanto objeto, entre linguagem escrita e compreensão, memória, inferência e pensamento". (KLEIMAN, 1999, p. 31).

A leitura compreende a mobilização de conhecimentos prévios (conhecimento linguístico, de mundo e textual), estes são determinantes para que, a partir da materialidade do texto, das pistas deixadas pelo autor, os leitores possam fazer inferências, levantar hipóteses, etc, para construção do sentido do texto.

$\mathrm{KOCH}$ e $\operatorname{ELIAS}^{2}$ (2006, p.09), por sua vez, apresentam três concepções de leitura resultantes das concepções de sujeito, de língua, de texto e de sentido,

\footnotetext{
${ }^{2}$ No escopo da Linguística Textual cujos estudos realizados, principalmente por Koch, sobre os aspectos da coerência textual trouxeram relevantes contribuições concernentes ao ensino e aprendizagem da leitura e escrita.
} 
possível de se adotar no trabalho com o texto, quais sejam: "foco no autor, foco no texto e foco na interação autor-texto-leitor".

A concepção "foco no autor" corresponde a "concepção de língua como representação do pensamento... e de sujeito psicológico, individual, dono de suas vontades e ações", ou seja, senhor do seu dizer. O texto é visto como um produto lógico na mente do escritor, cabendo ao leitor decifrar as intenções do autor. É um leitor passivo que apenas tenta decodificar a mensagem do texto. Nessa concepção a leitura é compreendida como "a atividade de captação das ideias do autor, sem se levar em conta as experiências e os conhecimentos prévios do leitor, a interação autor-texto-leitor com propósitos constituídos sócio-cognitivointeracionalmente". (KOCH e ELIAS, 2006, p. 10)

A segunda concepção, "foco no texto", assenta-se nos pressupostos da língua enquanto estrutura, como código - "mero instrumento de comunicação", de "sujeito determinado". Nesse sentido, o texto é compreendido como um artefato linguístico produzido por um emissor e que precisa ser decodificado pelo leitor, que para tanto só precisa dominar o código linguístico utilizado. O texto é visto como algo pronto, acabado, em que "tudo está dito no dito", cabendo ao leitor realizar uma leitura linear para reconhecer os sentidos das palavras e a estrutura do texto. Há uma preocupação com a estrutura superficial do texto. As duas concepções caracterizam o leitor como um sujeito passivo cuja tarefa principal na leitura é a de reconhecimento, de decodificação e de reprodução das ideias do autor. (KOCH e ELIAS, 2006, p. 11)

Esses modos de ler, como bem argumenta MARIANI (2002, p. 107), revelam que a leitura se resumiria a uma atividade limitante, a de "apenas decodificar significados estabilizados. Ou por outro lado, caberia ao leitor a tarefa de decifrar as intenções do autor. Leitura passiva, leitor manipulável, autor esfinge..."

Nesse contexto, a leitura era trabalhada como um ato mecânico, de forma descontextualizada e o papel do leitor era decodificar, extrair a mensagem do autor. Quem não se recorda das famosas questões de interpretação de texto, nos livros didáticos: "Qual a mensagem do texto?" ou "O que o autor quis dizer?". E o texto literário era utilizado como pretexto para a realização de exercícios de estruturas gramaticais da língua ou para identificar as características das escolas 
literárias. Esse segundo objetivo ainda persiste em alguns materiais didáticos do Ensino Médio.

De modo diferente, na concepção "interacional (dialógica) da língua, os sujeitos são vistos como atores/construtores sociais, sujeitos ativos que dialogicamente - se constroem e são construídos no texto" (grifos no original). Assim, o texto não é compreendido como mero repositório de informações, mas como o lugar em que autor e leitor interagem e se constituem enquanto sujeitos nos processos de interlocução. (KOCH e ELIAS, 2006, p. 12).

O sentido (ou sentidos) do texto é uma construção que se estabelece nessa interação, não sendo, portanto, algo que exista a priori. Um texto só terá sentido se algum leitor se predispuser a estabelecer uma relação intersubjetiva com quem o produziu. Assim, para além da atividade de decodificação das palavras e captação das ideias e intenções do autor, a leitura é uma atividade de interação e de construção de sentido(s) que exige um leitor ativo, crítico e reflexivo.

Esse modo de ler pressupõe um leitor engajado, replicante,

Responsivo, que ao perceber e compreender o significado (linguístico) do discurso, ocupa simultaneamente a ele uma ativa posição responsiva: concorda, ou discorda dele (total ou parcialmente), completa-o, aplica-o, prepara-se para usá-lo, etc.; posto que [...] toda compreensão é prenhe de resposta, e nesta ou naquela forma a gera obrigatoriamente. (BAKHTIN, 2016, p. 24-25)

Nessa abordagem mais dialógica e discursiva da linguagem, a obra literária deve ser compreendida como o lugar onde o escritor/autor e leitor se constroem enquanto sujeitos, ou seja, "o leitor desloca a obra do escritor, e o escritor desloca o leitor, às vezes revelando nele um outro, diferente do que acreditava ser." (PETIT, 2009, p. 37)

A outra grande vertente de abordagem da leitura é a de caráter sóciohistórica, que concebe a leitura enquanto prática sociocultural, consoante os estudos na área da História Cultural da Leitura (CHARTIER, 1998, 1999, 2011) e dos Novos Estudos do Letramento (STREET, 2010, 2014 [1995]; KLEIMAN, 1995, 2004). 
Estudiosos da História Cultural defendem que a leitura não deve ser concebida como uma atividade que considera apenas a relação individual do leitor com o texto, na busca de sua interpretação, mais que isso, a leitura constitui-se como "uma prática criadora, produtiva, inventora", na qual a produção de significados é determinada por um variado conjunto de aspectos culturais e institucionais que caracterizam as diferentes práticas de leitura. (CHARTIER, 1999, p. 77).

Enquanto prática cultural, os modos de ler e compreender os textos são modelados pela conjuntura social vigente em determinada época e sociedade, ou seja, são as condições históricas que vão indicar as necessidades ou as capacidades de leitura. Estabelecendo uma certa hierarquização do que deve e como deve ser lido, e consequentemente, de uma certa imposição da boa leitura e do bom leitor, a exemplo que do acontece com a leitura exigida e proposta pela escola. (CHARTIER, 2011)

Nesse sentido, os modos de organização das práticas leitoras organizadas pelos professores de certa forma vão indicar "uma certa leitura" que nem sempre irá coincidir com as realizadas pelos alunos, visto que suas experiências leitoras podem ser diferentes.

No arcabouço teórico dos Novos Estudos do Letramento ${ }^{3}$, a leitura é concebida como uma prática social crítica - práticas e eventos de letramento, que não envolve apenas a aprendizagem de habilidades técnicas e cognitivas da leitura, mas está circunscrita aos diversos grupos sociais e aos contextos de usos da leitura e escrita, isto é, são práticas situadas.

Desse modo, as ideologias, as relações de poder e os valores que circunscrevem tais práticas passam a ser priorizados nos modos de conceber o trabalho com a leitura. As práticas de letramento são indissociáveis do contexto sociocultural onde ocorrem os eventos de letramento que envolvem a interação entre os sujeitos intermediada pelos textos considerando as relações sociais e a

\footnotetext{
${ }^{3}$ Os estudos do letramento ganham uma nova conotação nos anos 80 e 90 do século passado, quando um grupo de estudiosos dos Estados Unidos e do Reino Unido começou a incorporar nas suas pesquisas questões sociais e etnográficas (HEATH,1982-2004; STREET, 1983), passando a considerar a leitura e a escrita como práticas sociais determinadas por questões sócio-histórica-culturais - New Studies of Literacy (NSL), em português, Novos Estudos do Letramento (NEL).
} 
diversidade cultural e social dos sujeitos que participam de tais práticas. (STREET, 2014 [1995])

Essa perspectiva engloba os letramentos sociais referindo-se àquelas práticas de uso da escrita e da leitura realizadas em diferentes contextos que extrapolam os espaços formais de ensino, o que significa dizer que os sujeitos estão sempre inseridos em práticas letradas. Devendo-se, então, considerar os diferentes letramentos, os multiletramentos ${ }^{4}$ ao se incluir os textos multissemióticos e a diversidade de suporte nos quais estes são produzidos e veiculados.

Consoante essa concepção, as práticas de letramento são plurais e as realizadas nas/pelas instituições de ensino são entendidas como um tipo de letramento. Disso decorre a importância e a necessidade das escolas incluírem essa em suas ações pedagógicas essa perspectiva transcultural, no sentido de orientar os alunos a se situarem, de maneira mais efetiva, nas diversas práticas de letramentos, dentre as quais podemos incluir as práticas de letramento literário.

\section{Formação do leitor na perspectiva do letramento literário}

O ensino de leitura e a formação de leitores nas escolas têm sido objeto de estudo e de questionamento de vários estudiosos, sobretudo em relação ao ensino de literatura e do trabalho com o texto literário. Há um discurso corrente na comunidade escolar, e na sociedade de modo geral, sobre o desempenho das competências leitoras e sobre a falta do "gosto pela leitura" por parte dos alunos. Apesar da complexidade que a questão exige, alguns estudos têm indicado que, dentre outros aspectos, parte dessa problemática é proveniente das concepções de ensino de literatura que norteiam as propostas pedagógicas das escolas.

A esse respeito, REZENDE (2013, p. 109) argumenta que:

\footnotetext{
${ }^{4}$ Esse conceito e seus desdobramentos foram desenvolvidos por um grupo de pesquisadores denominado The New London Group (NLG), em português, O Grupo de Nova Londres (GNL) que, em 1996, lançou o manifesto chamado de "A pedagogy of multilteracies: designing social futures".
} 
Um dos jargões mais frequentes na escola é o de "formar leitores". Ora, mas que leitor? Leitor que não lê literatura, que tem contato com simulacros ou com chavões da história literária? $\mathrm{Na}$ perspectiva tradicional de formação do leitor, caberia ao ensino fundamental "despertar o gosto" e, ao ensino médio, um aprendizado sobre a execução das obras e sobre a história literária.

A provocação acima nos chama atenção para a importância e a necessidade de se repensar a finalidade e as práticas de ensino de literatura no espaço escolar, no sentido de se construir uma proposta pedagógica mais produtiva e significativa que, de fato, priorize a leitura do texto literário na formação de leitores.

Nesse sentido, COSSON (2012, p.17) postula que o ensino de literatura deve proporcionar a experiência literária que:

[...] não só nos permite saber da vida por meio da experiência do outro, como também vivenciar essa experiência. Ou seja, a ficção feita palavra na narrativa e a palavra feita matéria na poesia são processos formativos tanto da linguagem quanto do leitor e do escritor.

Para tanto, é necessário que o texto literário ocupe um lugar de destaque na escola por meio da promoção do letramento literário. Este é concebido como uma prática social e diferencia-se dos outros tipos de letramento devido à singularidade do texto literário e de sua função primordial na sociedade que se constitui na construção e reconstrução da "palavra que nos humaniza", nos termos de CANDIDO (1995, p.180).

Ainda para COSSON (2012, p. 24), o letramento literário permite que "a leitura literária seja exercida, sem o abandono do prazer do texto, mas com o compromisso de conhecimento que todo saber exige".

Nessa direção, a escola, enquanto agente de letramento, deve assumir a responsabilidade de priorizar as práticas de leitura literária que sejam mais significativas para o processo de constituição de leitores. Ou conforme discutido por SOARES (2011, p. 47), de que forma a escolarização da literatura pode conduzir "eficazmente às práticas de leitura literária que ocorrem no contexto social e às atitudes e valores próprios do ideal de leitor que se quer formar". Ideal não no sentido de um leitor idealizado, mas na direção das instituições de ensino 
terem clareza das concepções de leitura e de leitor que devem nortear suas práticas pedagógicas.

Desse modo, o letramento literário deve ser compreendido com um processo que permita aos alunos compreenderem, por meio do contato com a obra literária, o funcionamento dos modos de dizer do discurso literário e construam de maneira crítica os significados desse discurso para sua vida, enquanto leitores e para a comunidade na qual estão inseridos. Para tanto, a escola deve orientar os alunos a compreenderem e explorarem as singularidades da linguagem literária, visto que "ler implica troca de sentidos não só entre o escritor e o leitor, mas também com a sociedade onde ambos estão localizados, pois os sentidos são resultantes de compartilhamento de visões de mundo entre os homens no tempo e no espaço". (COSSON, 2006, p. 27)

O letramento literário não exclui a aprendizagem de outros saberes literários (conhecimento sobre a história da literatura, teoria e crítica literárias e os saberes e habilidades adquiridos com a leitura), porém deve enfatizar a aprendizagem que propicia a construção de saberes construídos por meio da experienciação do mundo por meio da palavra, ou seja, da leitura literária que nos auxilia a compreender o mundo e a nós mesmos. Embora a preocupação maior da escola, nas aulas de literatura, seja com o ensino sobre a história da literatura relegando a segundo plano a leitura do texto literário.

$\mathrm{Na}$ tentativa de ressignificar essa realidade COSSON (2012, p. 47-48) propõe alguns princípios que devem orientar o processo do letramento literário:

- O ensino de literatura deve ter como centro a experiência do literário, que não deve se limitar a leitura pura e simples da obra, mais que isso, as práticas de sala de aula devem considerar como os alunos compreendem e constroem significados para os modos de dizer literário. Cabe ao professor fazer um trabalho de maneira crítica para que os alunos possam construir esses saberes, levando-os a ultrapassar o simples consumo de textos literários;

- A literatura não pode ser reduzida ao sistema canônico devendo abarcar também as diversas formas de manifestação literárias, bem como a sua relação com outras artes e saberes;

- A construção de uma comunidade de leitores. É essa comunidade que oferecerá o repertório cultural a ser construído pelos leitores. Para tanto, é necessário um trabalho efetivo e contínuo com a leitura do texto literário, partindo do conhecido para o desconhecido, do simples para o 
complexo, do semelhante para o diferente, com o objetivo de ampliar e consolidar o repertório cultural dos alunos.

As leituras só para fins avaliativos ou para a realização de exercícios gramaticais ou para identificar as escolas literárias não têm lugar nessa proposta. Outra questão muito importante é que, ao se trabalhar com a diversidade cultural característica da sociedade, ajuda-se a escola a se abrir para outras expressões culturais que são excluídas de seus currículos, sobretudo àquelas representantes da cultura popular, para as semioses das linguagens e dos textos; além de valorizar muitos aspectos que estão presentes na realidade sociocultural dos alunos. "É preciso abrir as janelas, abrir o corpus das obras estudadas". (PETIT, 2013, p. 60).

Essa concepção se alinha ao proposto por SOARES (2008, p. 31) quando refletindo sobre a natureza ideológica da leitura literária advoga sobre sua importância não só para a democratização cultural, mas, sobretudo, para a democratização do ser humano, conforme demonstram suas palavras:

\footnotetext{
A leitura literária democratiza o ser humano porque mostra o homem e a sociedade em sua diversidade e complexidade, e assim nos torna mais compreensivos, mais tolerantes - compreensão e tolerância são condições essenciais para a democracia cultural.
}

A formação do leitor na perspectiva do letramento literário exige também uma nova postura do professor que, para além de mediador entre texto e leitor, deve atuar como agente de letramento, ou seja, aquele que é capaz de organizar a sua ação pedagógica priorizando as melhores estratégias para envolver os alunos nas diversas práticas de letramento na escola. (KLEIMAN, 2008)

\section{Os círculos de leitura como prática de letramento literário no contexto escolar}

Os círculos de leitura se constituem como uma prática privilegiada para formação de comunidades de leitores. A leitura coletiva reforça a construção social dos significados dos textos, fortalece os laços de solidariedade do grupo ao permitir que seus participantes compartilhem suas experiências, sentimentos etc. 
Contribui também para a troca de saberes e construção de novos conhecimentos de forma crítica e participativa.

A leitura coletiva em espaço público não exclui a leitura íntima, singular, subjetiva, pois cada leitor constrói os significados, os sentidos para suas leituras a partir de suas vivências, suas experiências, seu repertório. Acreditamos também que o compartilhamento de suas vivências pode propiciar a abertura dos leitores para o outro e para o mundo. É, portanto, exercício de alteridade, de altruísmo.

Outro fator importante é que a metodologia do círculo de leitura favorece o desenvolvimento de relações mais simétricas e dialógicas na comunidade de leitores. A realização do círculo exige duas etapas: a preparação e a execução. (COSSON, 2014)

A preparação compreende: (i) a seleção das obras que devem ser adequadas aos interesses da comunidade de leitores, nesse sentido o texto bom/adequado é aquele que favorece a leitura e discussão do grupo; e a sua escolha deve ser feita pelos leitores. Assim o professor deve buscar a estratégia mais coerente para realizar esse processo. Destaca-se que a obra não se limita ao texto verbal escrito ou ao suporte do livro, podendo ser escolhidos textos multissemióticos e diversos suportes; (ii) a disposição dos leitores que consiste em buscar conhecer a história de leitura dos participantes e articular estratégias que promovam a participação desses; (iii) sistematização das atividades que compreendem a organização do meio, do local e calendário dos encontros, os papeis de cada um nas reuniões e as regras de convivência.

A execução consiste em: (i) leitura oral realizada por um leitor guia ou coletiva da obra, podendo ocorrer também a leitura silenciosa. $O$ tempo dedicado à leitura irá depender do tipo da obra trabalhada e do perfil do grupo; (ii) o compartilhamento, que pode envolver uma preparação para a discussão, em que os leitores fazem anotações ou destacam pontos que acharam importantes durante a leitura, e a discussão propriamente dita, momento em que os leitores socializam suas impressões sobre o que leram, promovendo assim a troca de vivências e experiências, sem o julgamento da leitura certa ou errada; (iii) o registro é o momento em que os participantes refletem como estão lendo e sobre o funcionamento do grupo, assim como sobre a obra e as leituras compartilhadas. 
Uma estratégia interessante para realização do registro são os diários de leitura, as anotações ou comentários feitos pelos próprios alunos leitores.

Além dessas etapas é importante que se faça uma avaliação do funcionamento dos círculos e de seus resultados como a realização de uma atividade que pode ser uma produção escrita (diários de leitura, resenhas, comentários críticos etc.) ou outro tipo de produção (elaboração de vídeos, dramatização, etc.).

Convém salientar que a proposta de organização do círculo de leitura não é fechada, portanto, essas etapas podem ser ressignificadas e outras incorporadas, a depender do contexto e da comunidade de leitores participantes. Por exemplo, para leitura pode-se priorizar a obra de determinado autor ou uma temática abordada por vários autores, em diversos gêneros literários, suportes, e assim por diante.

O mais importante a ser considerado é que os círculos de leitura sejam trabalhados enquanto uma prática situada de letramento (letramento literário) que promova o encontro de leitores em torno do texto literário em um espaço coletivo.

A título de ilustração, apresentamos, de maneira sucinta, uma experiência desenvolvida com círculos de leitura ${ }^{5}$, envolvendo um grupo de 30 alunos do $9^{\circ}$ ano do ensino fundamental II e do primeiro ano do ensino médio, de uma escola pública da rede estadual, em atendimento à solicitação da direção da referida escola.

Feitos os primeiros contatos, a direção e a professora indicada para coordenar a realização do projeto, na escola, procederam à divulgação das atividades e mobilização dos alunos que constituíram o grupo de leitores.

Optamos pela metodologia do círculo de leitura do tipo semiestruturado, em que, para o seu funcionamento, basta combinar algumas orientações a serem seguidas pelos participantes. Assim, estabelecemos os seguintes procedimentos: na preparação (i) elaboração do calendário dos encontros do grupo de leitores; (ii) definição do local e horário dos encontros; na execução (iii) atividade inicial

\footnotetext{
${ }^{5}$ Atividade do Projeto Leitura Itinerante do Núcleo de Leitura Multimeios do Departamento de Letras e Artes da Universidade Estadual de Feira de Santana/UEFS, cujo objetivo principal é fomentar a formação de leitores de literatura em espaços formais e informais. A experiência foi realizada no período de agosto a dezembro de 2016, em articulação com o Projeto Novos Talentos, convênio firmado entre UEFS-CAPES.
} 
de acolhimento e entrosamento dos participantes; (iv) breve apresentação dos autores dos textos lidos, que era feita pelas professoras coordenadoras do projeto ( $v$ ) leitura silenciosa do texto momento que servia para os leitores fazerem suas anotações; (vi) leitura do texto em voz alta realizada por um (a) participante; (vii) discussão coletiva dos textos.

Como a proposição do projeto era trabalhar com o tema "os jovens e a cultura de massa", para início das atividades sugerimos a leitura do poema "Eu, etiqueta" de CARLOS DRUMMOND DE ANDRADE (2015). A discussão desse poema instigou não só a reflexão sobre o consumismo em nossa sociedade que valoriza o "ter" em detrimento do "ser", mas, sobretudo, como essa situação pode também gerar preconceito e discriminação social, visto que muitas pessoas são julgadas pela aparência ou por não terem condições para atender aos apelos da mídia consumista. Foi um momento bastante impactante para os alunos, muitos relataram situações em que eles próprios ou pessoas próximas sofreram algum tipo de discriminação devido à sua condição social e/ou étnico-racial.

Como desdobramento dessa primeira leitura, os alunos sugeriram que nos encontros seguintes fossem apresentados outros textos literários que abordassem a temática da discriminação e preconceito étnico-racial.

Assim, levamos para leitura os textos "Ousadia" e "Preto e Branco" de FERNANDO SABINO (1985); "Quem elegeu Barak Obama" de RONALDO CORREIA DE BRITO (2011); e "Distinções entre abolição da escravidão e racismo", "Antologia do quartinho de empregada no Brasil" e "Piadinha racista na boca de personagem negro na novela", do livro Sobre-Viventes! de CIDINHA DA SILVA (2016).

Durante a realização dos círculos, os alunos participaram de uma roda de conversa com a escritora Cidinha da Silva ${ }^{6}$, na qual tiveram a oportunidade de conhecer melhor sobre sua história de vida, sua obra e seu processo de criação.

\footnotetext{
${ }^{6}$ Atividade realizada durante a programação da IX Feira do Livro evento anual organizado pela Universidade Estadual de Feira de Santana e outros parceiros, que tem como missão promover o contato de crianças, jovens e adultos, com a palavra escrita, e assim, contribuir para a formação de leitores, em especial de literatura. Apresenta uma vasta programação cultural, educativa e recreativa, durante uma semana, sempre no mês de setembro. Em 2018, passou a ser denominada de Festival Literário e Cultural de Feira de Santana (FLIFS) - @flifsoficial.
} 
Momento também em que puderam socializar suas experiências de leitura dos textos da autora.

Esse episódio foi um incentivo a mais para que os alunos sugerissem a continuidade de leitura de outros textos do livro. Demos prosseguimento aos círculos de leitura com uma pequena reorientação, ou seja, a cada encontro uma dupla de alunos ficava responsável pela leitura prévia e indicação do texto que seria lido e discutido coletivamente.

Os círculos de leitura aconteceram uma vez por semana, com duração de duas horas, em turno oposto ao horário das aulas dos participantes.

Nos encontros os alunos puderam expressar livremente como os textos tocaram suas subjetividades, falar sobre suas vivências pessoais e estabelecer relações intertextuais com outros gêneros e linguagens, a exemplo de letras de músicas e filmes. ${ }^{7}$

$\mathrm{Na}$ percepção dos alunos, a participação nos círculos de leitura se constituiu em momentos prazerosos de encontros e de reflexões nos quais puderam enxergar a si e ao outro, além de permitirem um olhar mais crítico sobre a realidade ao revelarem uma postura não conformista diante das situações suscitadas pelos textos. Ao contrário, para eles, a vivência com o texto literário serviu para despertar a importância do engajamento da juventude para a desconstrução de certos discursos que reproduzem as relações de desigualdade em nossa sociedade. Pois, como bem argumenta PETIT (2009, p. 41):

[...] Se o fato de ler possibilita abrir-se para o outro, não é somente pelas formas de sociabilidade e pelas conversas que se tecem em torno dos livros. É também pelo fato de que ao experimentar, em um texto, tanto a sua verdade mais íntima como a humanidade compartilhada, a relação com o próximo se transforma. Ler não isola do mundo. Ler introduz no mundo de forma diferente. $O$ mais íntimo pode alcançar neste ato o mais universal.

\footnotetext{
${ }^{7}$ Além dos momentos de leitura nos círculos foram realizadas outras atividades como: a exibição e discussão do vídeo (História das coisas) e do filme (Que horas ela volta?), visitas à exposição de arte no Museu do Centro de Cultura e Artes da cidade e no Museu Regional Casa do Sertão da UEFS. Também foram realizadas leituras de outros gêneros textuais, a exemplo de charges, letras de músicas (reggae, hap e hip hop).
} 
A liberdade para expressar opiniões sem a preocupação com a resposta certa ou errada e a leitura compartilhada possibilitaram a construção de um ambiente participativo, de respeito mútuo e de solidariedade entre os participantes. Muitos alegaram que não interagiam nas aulas, devido ao receio de críticas de professores e colegas. Porém, a participação nos círculos contribuiu para mudança dessa postura. Fato reafirmado pela professora coordenadora do projeto ao ressaltar uma maior participação desses alunos nas aulas e em outras atividades realizadas na escola, sobretudo, uma maior frequência à biblioteca escolar.

Além de todos esses aspectos, a participação nessa experiência serviu de inspiração para a prática da escrita literária. Muitos alunos escreveram poemas e crônicas espelhando-se nas histórias dos textos lidos, produção que foi socializada no encerramento do projeto.

Por fim, acreditamos que essa experiência evidencia uma possibilidade de trabalho com a leitura literária na escola que ajude a revelar narrativas e trajetórias outras dos sujeitos que se encontram com os textos. É a importância da leitura crítica que auxilia no processo de libertação e resistência dos sujeitos. (FREIRE, 1989)

$\mathrm{Na}$ avaliação todos os envolvidos destacaram a importância da realização dessas atividades com os jovens e do compromisso da direção e professores darem continuidade ao que foi iniciado, inclusive alguns alunos se prontificaram a serem multiplicadores da experiência na escola.

\section{Considerações finais}

A formação de leitores ainda se constitui em grande desafio para os professores, sobretudo, de leitores de literatura. Mesmo reconhecendo a importância da escola como principal agência de letramento na sociedade, ainda há muitas críticas em relação ao ensino de literatura, que em muitos casos, prioriza o ensino da história literária ou de elementos da crítica e não promove o encontro do leitor com o texto literário. Em muitos casos, se limitando a leitura de fragmentos de textos e resumos de obras presentes no livro didático. 
A perspectiva dos letramentos literários, que concebe a leitura enquanto prática social situada e determinada pelos seus contextos de uso, apresenta algumas contribuições para a formação de leitores de literatura, na escola, ao trazer para o centro das práticas de leitura, a vivência e experiência dos leitores com os textos literários em sua diversidade de manifestações e suportes presentes na sociedade (diversidade dos gêneros literários, textos clássicos e contemporâneos, etc).

Para tanto, é fundamental que as propostas de ensino de literatura sejam ressignificadas, no sentido de que as escolas possam construir uma nova cultura literária que privilegie dentro do tempo escolar espaço para a vivência do literário, que contribua de modo mais efetivo para a formação de leitores críticos, proficientes que possam levar suas experiências leitoras para outros contextos de suas vidas. E, sobretudo, que sirva "para que os jovens se tornem um pouco mais atores de suas vidas, um pouco mais donos de seus destinos e não somente objetos do discurso dos outros." (PETIT, 2009, p. 100)

\title{
LITERARY LITERACY AND THE TRAINING OF READERS IN A SCHOOL CONTEXT
}

\begin{abstract}
It is presented in this paper a reflection on the important and complex school task that is to train literature readers. Initially, we highlight two main approaches to reading in the field of Applied Linguistics. Firstly, the psychosocial, which is based on the psychological sciences (Psycholinguistics and Cognitive Psychology) and, secondly, the socio-historical, with emphasis on the conception of reading proposed by the New Studies of Literacy, which conceives reading as a social practice limited to the real contexts of language use (STREET, 2014). We aim to demonstrate how these approaches have impacted or impact on the work with reading in schools. We then discuss more specifically the contributions of literacy studies with an emphasis on literary literacy assumptions for the teaching of literature. From this perspective, work with reading should consider the following principles: the "literary experience", "not reducing to the canonical system" and "building a community of readers" (COSSON, 2012, 2014). Finally, we propose the reading circle as a literary literacy practice that can contribute to the formation of critical and proficient readers in the school context.
\end{abstract}

Keywords: Training of readers. Literary reading. Literary literacy. Reading conceptions.

\section{Referências}

ANDRADE, Carlos Drummond de. Eu, Etiqueta. In: Corpo. 1 ed. São Paulo: Companhia das Letras, 2015. p. 53-55 
AZEVEDO, Ricardo. Formação de Leitores e razões para a literatura. In: SOUZA, Renata Junqueira de (Org.) Caminhos para a formação do leitor. 1.ed. São Paulo: DCL, 2004, p.38-47

BAKHTIN, Mikhail. Os gêneros do discurso. Trad. Paulo Bezerra. 1 ed. São Paulo: Editora 34, 2016.

BRITO, Ronaldo Correia de. Quem elegeu Barack Obama. In: Crônicas para ler na escola. Rio de janeiro: Objetiva. p. 107-108. 2011

CANDIDO, Antonio. $O$ direito à literatura. In: Vários escritos. São Paulo: Duas Cidades, 1995, p. 169-191.

CHARTIER, Roger. A aventura do livro: do leitor ao navegador, Tradução Reginaldo de Moraes. São Paulo: Editora UNESP, 1999

CHARTIER, Roger. (Org.) Práticas da Leitura. Tradução Cristiane Nascimento, 5 ed. São Paulo: Estação Liberdade, 2011.

COSSON, Rildo. Círculos de leitura e letramento literário. São Paulo: Contexto, 2014.

COSSON, Rildo. Letramento Literário: teoria e prática. São Paulo: Contexto, 2012.

FREIRE, Paulo. A importância do ato de ler: em três artigos que se completam. São Paulo: Autores Associados:Cortez.1989

KLEIMAN, Angela B. Abordagens da leitura. SCRIPTA. Belo Horizonte, v.7. n. $14.1^{\circ}$ sem., p. 13-32, 2004

KLEIMAN, Angela B. Oficina de leitura: teoria e prática. 4.ed., Campinas: Pontes Editora, 1996.

KLEIMAN, Angela B. Texto e Leitor: aspectos cognitivos da leitura. São Paulo: Pontes, 1989

KLEIMAN, Angela B. Os estudos de letramento e a formação do professor de língua materna. In: LINGUAGEM EM (DIS)CURSO-LEMD, v. 8, n. 3, set/dez, p. 477-517, 2008. Disponível em: www.scielo.br/pdf//d/v8n3/05.pdf. Acesso em: 25.09.2017.

KLEIMAN, Angela B. (Org.) Os significados do letramento: uma nova perspectiva sobre a prática social da escrita. Campinas. São Paulo: Mercado de Letras, 1995.

$\mathrm{KOCH}$, Ingedore Villaça, ELIAS Vanda Maria. Ler e compreender: os sentidos do texto. São Paulo: Contexto, 2006. 
LEAHY, Cyana. Relembrando algumas premissas fundamentais. In: PAIVA et al (Orgs.) Democratizando a leitura: pesquisas e práticas. 1 ed. Belo Horizonte: Ceale; Autêntica, 2008, p. 199-206

MARIANI, Bethania Sampaio Corrêa. Leitura e condição do leitor. In. YUNES, Eliana (Org.) Pensar a leitura: complexidades. Rio de Janeiro. Ed. PUC-Rio, São Paulo: Loyola, 2002, p.107-109

PETIT, Michèle. Leituras: do espaço íntimo ao espaço público. Trad. Celina Olga de Souza. 1 ed. São Paulo: Editora 34. 2013

PETIT, Michèle. Os jovens e a leitura: uma nova perspectiva. Trad. Celina Olga de Souza. 2 ed. São Paulo: Editora 34. 2009

REZENDE, Neide Luzia de. O ensino de literatura e a leitura literária. In: DALVI, Maria Amélia; REZENDE, Neide Luzia de; Rita, JOVER-FALEIROS (orgs.). Leitura de literatura na escola, São Paulo-SP: Parábola, 2013, p. 99-112

SABINO, Fernando. Ousadia. In: A mulher do vizinho. São Paulo: Círculo do Livro S.A, 1985, p. $199-201$.

SABINO, Fernando. Preto e Branco. In: A mulher do vizinho. São Paulo: Círculo do Livro S.A, 1985, p. 203 - 204.

SILVA, Cidinha da. Sobre-viventes! 1 ed. Rio de Janeiro: Pallas. 2016.

SILVA, Ezequiel Theodoro da. Concepções de leitura e suas consequências no ensino. PERSPECTIVA. Florianópolis, v.17, n. 31, p. 11 - 19, jan./jun, p. 11-19, 1999

SOARES, Magda. A escolarização da literatura infantil e juvenil. In: EVANGELISTA, Aracy Alves Martins; BRANDÃO, Heliana Maria Brina; MACHADO, Maria Zélia Versiani (orgs.). A escolarização da leitura literária: $O$ jogo do livro infantil e juvenil. 2 ed., Belo Horizonte: Autêntica. 2011, p.17-48

SOARES, Magda. Leitura e democracia cultural. In: PAIVA et al (Orgs.) Democratizando a leitura: pesquisas e práticas. 1 ed. Belo Horizonte: Ceale; Autêntica, 2008, p.17-34

STREET, Brian V. Os novos estudos do letramento: histórico e perspectiva. In: MARINHO, Marildes, CARVALHO, Gilcinei Teodoro (Orgs,) Cultura escrita e letramento. Belo Horizonte: Editora UFMG, 2010, p. 33-53.

STREET, Brian V. Letramentos Sociais; abordagens críticas do letramento no desenvolvimento, na etnografia e na educação. Tradução Marcos Bagno, 1.ed. São Paulo: Parábola Editorial, 2014 [1995].

Data da Submissão: 14/11/2019

Data da Aprovação: 26/12/2019 